\title{
Technical Analysis in the Foreign Exchange Market: A Cointegration-Based Approach*
}

\author{
Norbert Fiess \\ University of Strathclyde, U.K. \\ Ronald MacDonald \\ University of Strathclyde, U.K.
}

Most technical analysis studies are concerned with the profitability of technical trading rules and almost all of them focus exclusively on trendfollowing patterns. In this paper we examine a different kind of technical indicator which suggests a structural relationship between High, Low, and Close prices of daily exchange rates. Since, for a given exchange rate, it can be shown that these prices have different time series properties, it is possible to explore the structural relationships between them using multivariate cointegration methods. This methodology facilitates the construction of dynamic structural econometric models, which are used to derive dynamic outof-sample forecasts over different time horizons. Compared to standard benchmarks, it turns out that these models have extremely good forecasting properties, even when allowance has been made for transactions costs and risk premia (JEL: F31, G12).

Keywords: exchange rates forecasting, technical analysis

\section{Introduction}

Although technical analysis (TA) ${ }^{1}$ is often dismissed in the academic literature, because of its lack of theoretical underpinnings, its popularity has always been high amongst practitioners. For example, in

*The authors are grateful to three anonymous referees for helpful comments on an earlier draft of this paper. The usual disclaimer applies.

1. That is, the use of a broad class of prediction rules for forecasting financial prices.

(Multinational Finance Journal, 1999, vol. 3, no. 3, pp. 147-172)

CMultinational Finance Society, a nonprofit corporation. All rights reserved.

DOI: $10.17578 / 3-3-1$ 
a recent survey of German foreign exchange market participants, Menkhoff (1998) showed that there is widespread use of technical analysis by traders and institutional investors for short to medium-term forecasts (similar findings were reported by Cheung and Chinn [1999] in a US-based study). A number of studies has indicated that technical trading based on simple filter rules can be highly profitable, relative to a buy-and-hold strategy, even when adjusted for transaction costs (see, for example, Dooley and Shafer [1983], Sweeny [1986] and, more recently, Levich and Thomas [1993]). ${ }^{2}$

In this paper we seek to take recent academic work on technical analysis one step further. In particular, a common feature of extant studies is that the trend-following indicators are normally calculated on a close-of-price basis. However, a different class of technical indicators, widely used among foreign exchange traders, exploits the fact that certain values for a price series appear to have a higher informational content than others. On a daily basis, these correspond to the two extremes: the highest and lowest prices of the day, and the opening and closing price of the market. ${ }^{3}$ The difference between High and Low represents the trading range and gives information about the trading activity of a certain period. Given a specific High and Low, the Close price supposedly contains information about future price development. Since it can be shown that High, Low, and Close prices of the same exchange rate series have different time series properties, ${ }^{4}$ we propose exploring the structural relationships between these prices using multivariate cointegration methods. We find that, by restricting the cointegration space, it is possible to empirically identify 'long-run' relationships in the data that coincide with the underlying structure of this class of technical analysis. Further, using dynamic modeling

2. Schulmeister (1987), Leoni (1989), and Menkhoff and Schlumberger (1995) additionally take moving average-based indicators and momentums into consideration.

3. Since foreign exchange is traded around the world and around the clock, the foreign exchange market never really closes. It is, nevertheless, conventional to report an opening and closing price. On a daily basis, the Close price corresponds to $5 \mathrm{pm}$ New York time when trading in NY ceases and Sydney prepares to start its currency trading. On weekdays, closing prices are identical to the opening prices, since they are recorded at the same point in time, Open and Close prices differ only on weekends and holidays when there is a considerable length of nontrading in the currency market. For example, for a weekend, the market closes at $5 \mathrm{pm}$ NY time on Friday and opens again at 8 am Sydney time on Monday.

4. For example, a visual inspection of the autocorrelation functions of the price series used in this paper indicated that they had different time series properties. 
techniques, we are able to use the identified structural relationships to derive dynamic out-of-sample forecasts over different time horizons. These models produce a creditable out-of-sample forecasting performance in terms of beating a martingale, and also in terms of their ability to generate significant directional ability. Perhaps most significantly, our forecasting performance does not disappear when risk and transaction costs are allowed for.

The outline of the remainder of this paper is as follows. In the next section we briefly outline the concept of a stochastic, which is a technical indicator that ties down the relationship between High, Low, and Close. In section 3 the data set used in this study is discussed and some preliminary statistics are presented. The econometric methodology is presented in section 4, along with our estimated results. The forecasting performance of our models is assessed in section 5 in terms of beating a random walk and directional ability, while in Section 6 the implied profitability of the different exchange rate models is compared to a buy-and-hold strategy. A conclusion is presented in Section 7.

\section{The Stochastics}

Rather than just displaying the relationship in a graphical way, the Stochastics introduced by George Lane (1984) tries to quantify the relationship between High, Low, and Close prices in order to generate a clear trading signal. The Stochastics derives a trading signal using the following formula:

$$
\begin{gathered}
\% K=100\left(\frac{C_{t}-L_{t}^{\min }}{H_{t}^{\max }-L_{t}^{\min }}\right) \\
\% D=\frac{1}{n} \sum_{i=1}^{n} \% K_{t-i+1}
\end{gathered}
$$

where $C_{t}$ is today's close, $H_{t}^{\max }$ is the biggest high of a certain moving period, and $L_{t}^{\min }$ is the corresponding lowest low for the same period. Having established these values, $\% K$ generates a signal which can take on values between 0 and 100. A common practice among technical analysts is to calculate $H_{t}^{\max }$ and $L_{t}^{\min }$ over the last 14 periods and $H_{t}^{\max }$ $-L_{t}{ }^{\mathrm{min}}$ denotes the so-called trading range of a given period and can be 
interpreted as a basic measure of volatility. The term $C_{t}-L_{t}^{\min }$ defines the upward potential of a given trading range. The Stochastics thus weight the upward potential of a given period with the volatility of that period. $\% D$ represents a smoothed version of $\% K$, where the smoothing factor used is normally $n=3$ periods.

The Stochastics can be traded in many different ways. Since the actual trading techniques used are not of interest in this study, the reader is referred to the literature on TA (e.g., Murphy 1986). For our purposes it is simply worth noting that the Stochastics is commonly interpreted as a so-called overbought-oversold indicator. The idea behind an overbought-oversold indicator is closely linked to the concept of the trading range and to support and resistance levels. Technical analysts refer to trading ranges as the price range within which an asset has been traded in the past and which can be characterized by the maximum and minimum of the price series. As long as prices do not break out of the recent trading range, the borders of the trading range act as support and resistance levels. ${ }^{5}$ Support and resistance levels confine the price dynamic until enough buying or selling interest is gathered in order to break through the upper or lower boundary of the present trading range. As a consequence, a new trading range is then established, where -- in the case of a break-out through the top of the trading range -- former top levels (resistance levels) will now become new bottom levels (support levels). (See Edwards and Magee, 1992, p.255.)

Since the Stochastics measure the trading range over a moving period, it should be possible to capture the trading activity over time fairly well. The implication of an overbought-oversold indicator is that, once the exchange rate comes close to the extremes of the range, a reversion to the center of the trading range is expected. Stochastic values between 70 and 100 are considered as strongly indicating an overbought situation; that is, currency A has appreciated rather sharply against currency B and now a correction of this "exaggerated" price movement is expected. Stochastic values below 30 are considered as strongly oversold. Both regions have the implication of the expectation

5. Edwards and Magee (1992, p.253) provide a definition of support and resistance that link support and resistance to supply and demand and thus selling and buying activity of speculative assets. For example, DeGrauwe and Decupere (1992) use 11 years of daily exchange rate data for USDDEM and USDJPY to show that certain price levels coinciding with round numbers -- such as 1.500 for USDDEM or 100.00 for USDJPY -- represent psychological barriers that might initiate buying or selling activity and hence act as substantial support and resistance levels. 
of a change in the direction of the price movement. Due to the set-up of the Stochastics, a value of 50 indicates the middle of the range and, therefore, no change in the exchange rate is expected. When trading the Stochastics as an overbought-oversold indicator, the exchange rate can be seen as a form of mean-reverting process. However, the mean does not correspond to the absolute sample mean but to the average of the periodic extremes:

By setting $\% K=50$ in (1) and re-arranging yields:

$$
H_{t}^{\max }-L_{t}^{\min }=2\left(C_{t}-L_{t}^{\min }\right)
$$

Adding $L_{t}^{\min }$ twice to both sides of the equation and re-arranging yields:

$$
\begin{gathered}
C_{t}=.5\left(H_{t}^{\max }+L_{t}^{\min }\right)=.5 H_{t}^{\max }+.5 L_{t}^{\min }, \text { or } \\
C_{t}-.5 H_{t}^{\max }-.5 L_{t}^{\min }=0,
\end{gathered}
$$

which translates into a vector of parameters as:

$$
(1,-.5,-.5,0) \text {. }
$$

The Stochastics thus establish a structural relationship between today's Close and the Maximum and Minimum price of a moving period, measured as the highest High and lowest Low. This structural relationship represents a testable hypothesis and we demonstrate in the next section that it is possible to identify a long-run relationship in the exchange rate data that comes close to the empirical counterpart. By incorporating this cointegrating relationship into short-run dynamic models, we are then able to present out-of-sample forecasts based on the dynamic representation of the exchange rate system. We take a good forecasting performance of our model as an indication that TA methods can be thought of as capturing any latent Granger causality that exists in the data.

\section{Data Sources and Preliminary Statistics}

Daily data from August 1986 to August 1996 for the High, Low, Open, and Close prices for the US Dollar/German Mark (USDDEM) and US Dollar/Japanese Yen (USDJPY) were used, yielding 2770 observations 
for each series. The data were log-transformed and checked for outliers and missing observations. Obvious outliers were removed and missing observations in the series were closed by linear interpolation. The data set was obtained from Knight Ridder Financial Ltd.

Since non-stationarity is a pre-condition of cointegration, the daily data for the two exchange rate series on High, Low, Open, and Close prices was tested for unit roots using Augmented Dickey Fuller (ADF) and Phillips Perron tests. All eight series appeared to be $I(1)$ in levels and $I(0)$ in first differences. The results of the unit root tests are available from the authors upon request.

\section{Econometric Methods and Results}

\section{A. Structural Econometric Modeling}

Our modeling strategy follows recent developments in the econometric literature, in particular the work of Clements and Mizon (1991), Hendry and Mizon (1993) and Johansen (1988), and we label it structural econometric modeling. ${ }^{6}$ Via a series of testable restrictions and reductions, this modeling strategy transforms an initial vector autoregressive model (VAR) in levels into a set of linear structural equations that incorporate both long and short-run dynamics.

Starting from an unrestricted VAR, the hypothesis of cointegration is formulated as a hypothesis of reduced rank of the long-run impact matrix $\Pi$. The VAR is generated by the vector $z_{t}$, which defines the potential endogenous variables of the model. The unrestricted VAR can be reparameterised into

$$
\begin{gathered}
\Delta z_{t}=\Gamma_{1} \Delta z_{t-1}+\ldots+\Gamma_{k-1} \Delta z_{t-k=1}+\Pi z_{t-k}+\psi D_{t}+\varepsilon_{t}, \\
\varepsilon_{t} \sim \operatorname{IN}(0, \Sigma),
\end{gathered}
$$

where the estimates of $\Gamma_{i}=-\left(I-A_{1}-\ldots-A_{i}\right),(1, \ldots, k-1)$ describe the short-run dynamics to changes in $z_{t}, \Pi=-\left(I-A_{1}-\ldots-A_{i}\right)$ captures the long-run adjustments, the $A$ matrices are the autoregressive parameter matrices from the unrestricted VAR, and $D$ contains deterministic terms.

6. A recent application of this modeling technique in the field of exchange rate economics is MacDonald and Marsh (1997). 
Additionally, if the data cointegrate $\Pi$ must be of reduced rank $r<p$, where $p$ is the number of variables entering the vector $z$ and $\mathrm{r}$ is the number of cointegrating relationships. In this case, $\Pi$ can be factored as $\Pi=\alpha \beta^{\prime}$, where $\beta$ and $\alpha$ are pxr matrices, which give the coinetgrating vectors and associated adjustment matrix, respectively.

This modelling strategy involves the transformation of the initial VAR into a constrained VAR (CVAR) by placing restrictions on the cointegration space. Secondly, the CVAR is then made more parsimonious (PVAR) by successively removing insignificant shortterm variables, based on $F$-tests, until all remaining variables are significant at the 5\% level. This PVAR is then transformed into a simultaneous equation model (SEM) by determining the short-term causality among the system variables. In order to reduce the dimensionality of the system further, by increasing robustness to changes, the individual equations are then finally estimated with Full Information Maximum Likelihood estimation (FIML). Considering the data-driven nature of the identification procedure, an important test statistic is the ability of the SEM to parsimoniously encompass the PVAR (see Clements and Mizon [1991]). A specific set of equations represents an acceptable parameterization of the original VAR, if it contains roughly the same information as the PVAR from which it was derived, given the restrictions imposed.

\section{B. Cointegration and the Stochastics}

The Stochastics establish a structural relationship between the Close of today and the Maximum and Minimum price of a moving period, measured as the highest High and the lowest Low. Specifying a VAR with the data vector $z_{t}=\left(C_{t}, H_{t}^{\max }, L_{t}^{\min }\right)$ for USDDEM and USDJPY and testing for cointegration between the three variables should reveal if, when using the Stochastics, an investor is intuitively exploiting Granger causality among the three series. Each VAR included a constant in the cointegration space and 15 lags of each of the variables, which was sufficient to produce random errors. ${ }^{7,8}$

7. The deterministic components of the VAR were defined according to the rank test based on the so-called Pantula test (see Johansen [1992]). The rank test suggests the inclusion of a constant in the cointegration space for both currencies.

8. The model specifications for the two models are presented in the appendix in table A1. 
TABLE 1. Cointegration Tests

\begin{tabular}{|c|c|c|c|c|c|}
\hline $\begin{array}{l}\text { Null } \\
\text { Hypothesis }\end{array}$ & $\begin{array}{l}\text { Alternative } \\
\text { Hypothesis }\end{array}$ & USDDEM & USDJPY & $\begin{array}{c}95 \% \\
\text { Critical Value }\end{array}$ & $\begin{array}{c}90 \% \\
\text { Critical Value }\end{array}$ \\
\hline$\lambda_{\text {trace }}$ test & & $\lambda_{\text {trace }}$ value & $\lambda_{\text {trace }}$ value & & \\
\hline$H_{0}: \mathrm{r}=0$ & $r>0$ & 274.15 & 285.44 & 35.10 & 31.88 \\
\hline$H_{0}: r \leq 1$ & $r>1$ & 60.24 & 59.75 & 20.17 & 17.79 \\
\hline $\mathrm{H}_{0}: \mathrm{r} \leq 2$ & $r>2$ & 9.30 & 6.52 & 9.10 & 7.50 \\
\hline
\end{tabular}

Note: Normalizing the first vector on the first element and the second on the third yields the following estimates for $\beta$ and $\alpha$ (table 2).

The estimates of the trace statistics, $\lambda_{\text {trace }}$, (see Johansen [1988]) for both currencies, reported in table 1 , indicate up to two significant cointegration vectors for USDJPY, and up to three for USDDEM. However, based on a graphical inspection of the cointegration relationships, and on an analysis of the companion matrix, we used only the first two vectors for USDDEM.

Normalizing the first vector on the first element and the second on the third yields the following estimates for $\beta$ and $\alpha$ (table 2).

The results for USDDEM give evidence of two cointegration relationships in the data set comprising $C_{t}, H_{t}^{\max }$, and $L_{t}^{\min }$. In the presence of multiple cointegrating vectors, it is now common practice to try to interpret these vectors in an economically and statistically meaningful way. In order to test if these theoretical values are indeed identifying, we performed several hypothesis tests following the approach described in Johansen and Juselius (1992, 1994).

Since we have shown in (1) to (3') that a mean-reverting interpretation of the Stochastics requires the relationship $C_{t}=.5\left(H_{t}^{\max }\right.$ $+L_{t}^{\text {min }}$ ), the estimated coefficients of the normalized first cointegration vector should be close to their theoretical values $(1,-.5,-.5,0)$. We attempt to interpret the second vector as a structural relationship of the form $H_{t}^{\max }-L_{t}^{\min }=$ constant, i.e., a stationary spread between the periodic High and Low prices. In vector form, the second cointegration vector should be of the form $\left(0,1,-1,{ }^{*}\right) .{ }^{9}$ The second vector may be interpreted as an extreme-value volatility measure (see Parkinson [1988]). Since such terms are normally modeled as $I(0)$ processes, our finding of cointegration between the high and low prices would seem to

9. A* indicates that a variable has been left unrestricted. 
Technical Analysis in the Foreign Exchange Market

Insert table 2 
be consistent with this interpretation.

A joint test of these two restrictions for USDDEM is $\chi^{2}(3)=4.24(p$ value $=.24)$. The estimated value of the coefficient of the constant in the second cointegration vector, which is the only freely estimated parameter in the cointegration space, is -.041 . This parameter value suggests that the spread between $H_{t}^{\max }$ and $L_{t}^{\min }$ equals .041 (or $4.1 \%$, since $\log$ transformed values of the levels were used). The actual average spread between $H_{t}^{\max }$ and $L_{t}^{\min }$ over the period August 1989 August 1996 was 70 basis points, which translates into 3.8\% in log terms. Since the coefficient of the constant has an associated standard error of .002, a Wald test of the form:

$$
\left(\frac{-.041-(-.038)}{.002}\right)^{2}=2.25
$$

can be used to test the hypothesis that the estimated value equals its empirical counterparts. The Wald statistic, which is asymptotically distributed as $\chi^{2}$, does not reject this hypothesis, since $\chi_{.95}^{2}=3.84$.

The results of the tests for USDJPY indicate the existence of a similar structural relationship to USDDEM, since the null hypothesis of the first vector being given by $(1,-.5,-.5,0)$ and the second being equal to $(0,1,-1, *)$ could not be rejected $\left(\chi^{2}(2)=1.25, p\right.$-value $\left.=.53\right)$.

The cointegration space for our two exchange rate models is therefore, in the terminology of Johansen and Juselius (1994), both empirically and also economically identified, in the sense that the estimated coefficients can be interpreted from an economic point of view.

\section{Structural Econometric Forecasting Models}

We now use our identified cointegration relationships, and the SEM methods discussed above, to derive short-run dynamic forecasting models for USDDEM and USDJPY. Given the data-driven nature of the identification procedure, an important test statistic is the ability of the SEM to parsimoniously encompass the PVAR (see Clements and Mizon [1991]). A specific set of equations is taken to represent an acceptable parameterisation of the original VAR if it contains roughly the same information as the PVAR from which it was derived, given the restrictions imposed. As can be seen in tables 3 to 4, each of our models easily passes the Clement-Mizon LR test of over-identifying 
Technical Analysis in the Foreign Exchange Market

Insert table 3 
Multinational Finance Journal

insert table 4 
restrictions.

The identified model structures reveal that $\Delta H_{t}^{\max }$ and $\Delta L_{t}^{\min }$ have an immediate impact on $\Delta C$, while $\Delta H_{t}^{\max }$ and $\Delta L_{t}^{\text {min }}$ can be identified as $\mathrm{AR}(1)$ processes. This model structure is in line with the identified theoretical relationship embodied in the first cointegration vector which assumes that today's Close is affected by today's periodic Maximum and Minimum. Since the Maximum and Minimum series corresponds to local Maxima and Minima of the High and Low price series, it is not surprising that $\Delta C$ does not enter either $\Delta H_{t}^{\max }$ or $\Delta L_{t}^{\min }$.

Since the error correction components are highly significant in almost all system equations, it is clear that a single equation reducedform modelling strategy would not have been appropriate. An additional advantage of using a structural equation approach is that it provides us with a closed system that facilitates computation of fully dynamic multistep-ahead forecasts. The forecasted values of each variable are in this case fed back into the system to provide the basis for the forecasts of subsequent periods. As such, no unfair advantage is given to the model over the random walk.

\section{Out-of-Sample Forecasting Results}

Even though our model is able to forecast the Close, the periodic High $\left(H_{t}^{\max }\right)$ and the periodic Low $\left(L_{t}^{\min }\right)$ prices $n$-steps into the future, only forecasts of the Close series were considered. Only these forecasts represent "true" forecasts in the sense that they assign a certain value to a specific point in time, i.e., a forecast of tomorrow's Close represents a forecast of tomorrow's spot rate at the 1700 hour. A forecast of the periodic High $\left(H_{t}^{\max }\right)$ or Low $\left(L_{t}^{\mathrm{min}}\right)$, however, does not reveal any information at which time of day this value is to be expected and thus is of little use under market timing considerations.

The forecasting models were estimated over the first 2500 data observations, thus sparing roughly $10 \%$ of the total sample for forecasting. Since the classic paper of Meese and Rogoff (1983), the crucial factor in determining the worth of an exchange rate model is how well it forecasts in an out-of-sample context relative to a random walk, using the metric of the root mean square error (RMSE) criterion. In table 5, Theil statistics are calculated as the ratio of the RMSE of the forecasting model over the RMSE of a driftless random walk; a value 
TABLE 5. RMSE of driftless Random Walk and Theil statistics

\begin{tabular}{|c|c|c|c|c|}
\hline \multirow[b]{2}{*}{$\mathrm{n}:$} & \multicolumn{2}{|c|}{ USDDEM } & \multicolumn{2}{|c|}{ USDJPY } \\
\hline & USDMI: & USDMII: & USJYII & USJYII \\
\hline 1 & 1.012 & 1.044 & .995 & .993 \\
\hline 2 & 1.008 & 1.037 & $.986^{*}$ & .98 \\
\hline 3 & 1.003 & 1.031 & $.987^{*}$ & .979 \\
\hline 4 & .999 & 1.031 & $.986^{*}$ & .978 \\
\hline 5 & .999 & 1.040 & $.998^{*}$ & .99 \\
\hline 6 & .991 & 1.020 & .989 & .98 \\
\hline 7 & .997 & 1.017 & .989 & .98 \\
\hline 8 & .999 & 1.016 & .993 & .987 \\
\hline 9 & .996 & 1.012 & .99 & .986 \\
\hline 10 & $.995^{*}$ & 1.016 & .994 & .994 \\
\hline
\end{tabular}

Note: A I indicates the basic model while a II indicates the basic model extended to include the extra information discussed in the text. Significance according to the DieboldMariano procedure is indicated by $*$ for the $10 \%$ level and by $* *$ for the $5 \%$ level. $\mathrm{n}: n$-daysahead forecast.

equal to one indicates equal forecasting accuracy, a value smaller than one indicates that the forecasting model outperforms a random walk and a value greater than one indicates that the model does worse than a random walk. The significance of the Theil statistics are tested using the Diebold-Mariano procedure (1995) ${ }^{10}$ From an investor's point of view, a forecast that correctly predicts the direction of change is more useful than RMSE minimization, so we also present a test of directional forecasting ability (table 6). ${ }^{11}$ The significance of the directional forecasts is tested with the help of Cumby-Modest (1987) statistics.

Our models (USDMI and USJYI) have extremely good one-dayahead forecasting properties. While insignificant Diebold-Mariano statistics make it difficult to discriminate between our models and a random walk on grounds of RMSE, both our models clearly dominate a random walk when assessing the directional ability (USDMI: 55.8\%, $U S J Y I=57.3 \%)$. It is of particular interest that our one-day-ahead

10. When evaluating the Diebold-Mariano statistics, we use a Newey and West correction for heteroscedasticity and serial correlation (induced by overlapping observations with multi-step forecasts).

11. The RMSE statistics in Table 5 were calculated without a drift term since this produced higher RMSE compared to the non-drift model. However, to calculate directional forecasts, a drift term has to be included and this was estimated as the mean of the absolute changes of the Close series. 
TABLE 6. Directional Forecasting Performance

\begin{tabular}{llllllll}
\hline & \multicolumn{3}{c}{ USDDEM } & & \multicolumn{3}{c}{ USDJPY } \\
\cline { 2 - 4 } \cline { 6 - 7 }$n:$ & USDMI: & USDMII: & Random Walk & & USJYII & USJYII & Random walk \\
\hline 1 & $.558^{*}$ & .59 & .478 & & $.603^{* *}$ & $.579^{* *}$ & .419 \\
2 & .538 & $.551^{*}$ & .478 & & .544 & $.552^{*}$ & .419 \\
3 & .528 & .516 & .467 & & .555 & $.543^{*}$ & .405 \\
4 & .533 & .537 & .484 & & $.573^{*}$ & $.553^{*}$ & .459 \\
5 & .527 & $.576^{*}$ & .461 & & .549 & $.578^{*}$ & .361 \\
6 & .516 & .545 & .467 & & .572 & $.560^{*}$ & .37 \\
7 & .519 & $.564^{*}$ & .481 & & .574 & $.566^{*}$ & .355 \\
8 & .49 & .568 & .49 & & .591 & $.562^{*}$ & .372 \\
9 & .513 & $.575^{*}$ & .496 & & .579 & $.567^{*}$ & .4 \\
10 & .55 & .567 & .504 & .561 & .54 & .377 \\
\hline
\end{tabular}

Note: A I indicates the basic model while a II indicates the basic model extended to include the extra information discussed in the text. Significance according to the DieboldMariano procedure is indicated by $*$ for the $10 \%$ level and by $* *$ for the $5 \%$ level. $\mathrm{n}: n$-daysahead forecast.

model forecasts are significant according to the Cumby-Modest statistics. This indicates that a forecast based on a model derived using TA criteria is able to outperform a random walk on a time horizon as short as a day.

The declining forecasting ability of the TA models over time seems to be consistent with the view that Chartists revise their forecasts on a daily basis. It is interesting to see if the forecasting ability of the models can be altered by incorporating additional information without changing the underlying causality structure. Since $H_{t}^{\max }$ and $L_{t}^{\min }$ represent the highest High and the lowest Low over a time horizon of 14 days, additional information was added to the models by including High and Low prices as exogenous variables to the three system equations, the equations for $\Delta C, \Delta H i g h$, and $\Delta L o w$.

In particular, since the market can close at the daily Low or High, daily High and Low prices can be determined only after the Close price. ${ }^{12} \Delta$ High and $\Delta$ Low were therefore incorporated into the dynamic equation for $\Delta C$ as lagged variables. By noting that today's Maximum and Minimum are, by definition, directly linked to today's High and

12. Cointegration tests between daily High, Low and Close prices confirm this causality structure and show that High, Low and Close prices Granger cause each other with the Close series being prior to High and Low. (See Chapter 2 in Fiess [1999].) 
Low, ${ }^{13} \Delta H i g h$ and $\Delta$ Low were incorporated as unlagged variables into the dynamic equation for $\Delta H_{t}^{\max }$ and $\Delta L_{t}^{\min }$. Since a multi-step-ahead forecasting model requires a closed system, the $\Delta H i g h$ and $\Delta L o w$ series were modeled as AR(1) processes, and the order of the AR processes was determined using Ljung-Box Q statistics. Since the altered model structure is recursive, the model was estimated by OLS where all insignificant variables were removed until all remaining parameters proved to be significant at the $5 \%$ level.

In particular, High and Low prices were incorporated in the form of lagged differenced values in the equation of $\Delta C$. By noting that today's Maximum and Minimum are by definition directly linked to today's High and Low, $\triangle H i g h$ and $\Delta$ Low were incorporated as unlagged variables into $H_{t}^{\max }$ and $L_{t}^{\min }$. Since a multi-step-ahead forecasting model requires a closed system, we modeled the High and Low series as AR(1) processes. The order of the AR processes was determined using LjungBox Q statistics. Since the altered model structure is recursive, the model was estimated by OLS where all insignificant variables were removed until all remaining parameters proved to be significant at the $5 \%$ level.

The incorporation of additional information in the form of High and Low prices (USDMII) boosted the directional forecasting ability for USDDEM, as can be seen by comparing the results in table 6 . Of particular interest is the increase from $55.8 \%$ to $59 \%$ in the one-stepahead horizon. In a similar fashion as for USDDEM, additional information was added to the USDJPY model. While the directional forecasting of the new USDJPY model (USJYII) also easily outperformed the random walk model with respect to directional forecasting ability, it could not match the performance of USJY I. However, unlike the directional forecasts of USJYI, the directional forecasts of USJYII proved almost exclusively significant according to the Cumby-Modest statistics.

\section{Assessing the profitability of the forecasting models}

In this section we test the profitability of our forecasting model. ${ }^{14}$ Since

13. Maxima and Minima are calculated as local extremes of Highs and Lows over the last 14 days.

14. For this profitability analysis, we select the models with the best directional ability, 
the Stochastics is a trading rule, rather than a forecasting model, we view this as a more appropriate method of assessment than the academic benchmark of a random walk.

To construct profitability estimates, we transform our forecasting models into trading models by defining a vector that issues exactly defined trading signals. Since our models work most successfully at the one-day-ahead horizon, a Buy signal (Long position) is issued if the one-day ahead forecast exceeds the current Close, and a Sell signal (Short position) is given if tomorrow's forecast lies below the current Close.

The Stochastics, on the other hand, can be traded in many different ways. However, since all of these strategies are effectively variations of the following two strategies, we focus on them here. Concentrating on $\% \mathrm{~K}$ alone, the Stochastics can be treated as a so-called OverboughtOversold Indicator, where a Buy signal is given if the Stochastics fall below values of 30 and a Sell signal arises if the Stochastics rise above 70 (Stochastics 70/30). Alternatively, many traders use the intersection between $\% K$ and its smoothed version, $\% D$, as a trading system (Stochastics Crossover). In this case, a Long signal is given, if $\% K$ rises above $\% D$ and a Short signal corresponds to a fall of $\% K$ below $\% D$. Since the Stochastics belong to the family of contra-trend indicators, and the majority of technical analysis studies focus on trend-following trading systems, a simple trend-following trading model based on a 10and a 20-day Moving Average was additionally considered (MA10/20). This trading model issues a Long signal if the 10-day Moving Average rises above the 20-day Moving Average. A Short signal is issued if the shorter term Moving Average falls below the longer-term Moving Average. ${ }^{15}$

i.e., USDM II for USDDEM and USJY I for USDJPY. The incorporation of High and Low prices, even though justified on causality grounds, might be seen as curve-fitting. To avoid this criticism, we also calculate the annualized profit for USDM I. This model leaves the investor with an annualized rate of return of $11.4 \%$ after accounting for transaction costs and net interest rate effects of $9.52 \%$. Even though USDM I cannot match the performance of USDM II, it still easily outperforms the buy-and-hold benchmark of $2.05 \%$ and other technical indicators.

15. Since we did not choose the $10 / 20$ day specification of the MA, or the 14-day specification of the Stochastics, on grounds of profitable ex post optimisation, the ex ante application of these two specific technical trading rules comes close to a real-world experiment, in the sense that they are the kinds of rules a trader would use to forecast 
We also include a simple trading strategy which aims to exploit mean-reversion within a trading range. For such a strategy (labeled, Revert), a Long signal is issued if the market closes below the middle of the current trading range. A Short signal is given if the current Close lies above the current center of the trading range. We consider two different specifications for the trading ranges: (1) a 14-day trading range as in the Stochastics and (2) a daily trading range, measured as the difference between the daily High and Low prices.

Assuming one US \$ investment per trading signal, and excluding the re-investment of speculative profits, our profitability calculations take three components into consideration: the cumulated daily return, the interest rate differential, and transaction costs. ${ }^{16}$ The returns series are calculated as the sum of cumulated single returns, where single returns are measured as the log-ratio of the exchange rate between opening and closing a foreign currency position. Since the trading models are active for different time spans, the cumulated returns are made comparable by annualization. The absolute returns are further adjusted for net interest rate effects using the methodology outlined in Schulmeister (1986).

The level of transaction costs is calculated as the percentage bid-ask spread of interbank quotes, and this is standard in other studies. ${ }^{17}$ The interbank quotation of bid and ask rates for USDDEM and USDJPY shows a usual spread of 3 basis points. Given an exchange rate of 1.5 DM and 100 Yen per 1 US\$, the estimated transaction costs per round trip, and thus per trading signal, are $.02 \%$ for USDDEM and $.03 \%$ of USDJPY. ${ }^{18,19}$

currency movements.

16. See Fiess (1999), Ch. 6.6, for a more detailed description of the methodology used in the profitability analysis.

17. An anonymous referee has pointed out that the use of the bid-ask spread may understate the true transaction cost. For example, other components of transaction costs are likely to include the setup and maintenance of the dealing room and trading facility.

18. Since the trading strategies investigated here involve switching from Short to Long positions or vice versa, i.e., neutral positions are excluded, each trading signal requires two transactions.

19. The level of transaction costs assumed here are slightly lower than the figures used by Sweeny (1986), Schulmeister (1987), and Menkhoff (1998), reflecting the declining spread in foreign exchange markets. However, they are still higher than figures quoted by bankers who told us in interviews that transactions costs average around $100 \mathrm{DM}$ per spot transaction 
We assess the profitability of the six different trading models starting from the simple profitability of following the trading signals and then add further aspects to the analysis by including a buy-and-hold benchmark and adjusting for risk premia. The results of the profitability analysis are summarized in table 7 . On pure profitability considerations, our model yields by far the highest annualized return rates, with $16.58 \%$ for USDDEM and $25.32 \%$ for USDJPY. While the Stochastics 70/30 also leaves the investor with a substantial annualized rate of return of $6.18 \%$ for USDDEM and $5.56 \%$ for USDJPY, the Stochastics Crossover, Moving Average 10/20, and the two mean-reverting trading models (Revert) perform poorly in comparison.

When the profitability of the different models is compared to a simple buy-and-hold strategy, the picture changes. ${ }^{21}$ A buy-and-hold strategy for USDDEM results in a fairly low annualized return rate of $2.05 \%$. The strong appreciation of the dollar against the Yen in the forecasting period makes a buy-and-hold strategy much more profitable for USDJPY. The resulting annualized rate of return of $16.25 \%$ establishes a difficult test criterion for our technical trading rules. While our models have no problem beating buy-and-hold for USDDEM as well as USDJPY, Stochastics 70/30 and MA10/20 both fail to outperform the buy-and-hold benchmark of $16.25 \%$.

Levich and Thomas (1993) show that the total return from following a trading strategy will overstate the true excess return if a risk premium is present, especially if currencies exhibit prolonged trends. To derive the true excess return, therefore, we calculated a risk premium for our sample period and adjusted this for the fraction of days long and short in foreign currency (see Levich and Thomas [1993]). For our model forecasts, and also for the Stochastics crossover, our earlier results are almost unaffected by including a risk premium. However, the MA 10/20 and Stochastics 70/30 models were affected by the inclusion of a risk premium, with the former model producing an expected annualized rate of return of only $4.14 \%$, while the latter produces an expected negative annualized rate of return of $-5.2 \%$.

and around 200 DM per forward transaction for USDDEM as well as USDJPY.

21. The profits of buy-and-hold are calculated as the difference in the exchange rate at the beginning and end of the forecasting period, acknowledging the net interest rate effect of investing in foreign rather than domestic money. 
TABLE 7. Profitability Profiles of Different Forecasting Models

\begin{tabular}{|c|c|c|c|c|c|}
\hline & Model & Revert & $(70 / 30)$ & $\begin{array}{l}\text { Stochastics } \\
\text { Crossover }\end{array}$ & $\begin{array}{l}\text { Stochastic } \\
\text { Ma } 10 / 20\end{array}$ \\
\hline \multicolumn{6}{|l|}{ USDDEM: } \\
\hline days long & $127(48 \%)$ & $121(49 \%)$ & $137(53 \%)$ & $119(49 \%)$ & $121(49 \%)$ \\
\hline days short & $135(52 \%)$ & $127(51 \%)$ & $122(47 \%)$ & $125(51 \%)$ & $116(51 \%)$ \\
\hline annual rate & $19.38 \%$ & $-4.35 \%$ & $6.7 \%$ & $-1.81 \%$ & $-.2 \%$ \\
\hline -incl. transaction costs & $16.63 \%$ & $-4.76 \%$ & $6.33 \%$ & $-4.39 \%$ & $-5.55 \%$ \\
\hline -incl. trans \& net interest & $16.58 \%$ & $-4.8 \%$ & $6.18 \%$ & $-4.44 \%$ & $-5.29 \%$ \\
\hline \multicolumn{6}{|l|}{ USDJPY: } \\
\hline days long & $137(52 \%)$ & $88(35 \%)$ & $86(35 \%)$ & $118(49 \%)$ & $138(61 \%)$ \\
\hline days short & $125(48 \%)$ & $165(65 \%)$ & $161(65 \%)$ & $122(51 \%)$ & $87(39 \%)$ \\
\hline Annual rate & $28.87 \%$ & $4.75 \%$ & $7.63 \%$ & $-3.86 \%$ & $5.83 \%$ \\
\hline -incl. transaction costs & $25.1 \%$ & $4.08 \%$ & $7.17 \%$ & $-10.15 \%$ & $5.43 \%$ \\
\hline -incl. trans \& net interest & $25.32 \%$ & $2.66 \%$ & $5.56 \%$ & $-10.25 \%$ & $6.75 \%$ \\
\hline
\end{tabular}

Note: Numbers in brackets are percentages of days long or short. 


\section{Conclusion}

In this paper we have taken the relationship suggested by the technical indicator known as a stochastic to establish cointegration relationships in daily exchange rate data consisting of Close, periodic High, and periodic Low prices. Using the dynamic modeling strategy of Clement and Mizon (1991) and Hendry and Mizon (1993) and Johansen (1988), we were able to derive fully dynamic forecasting models for USDDEM and USDJPY, and these proved to significantly outperform a random walk at a time horizon as short as one day ahead; the estimated models were also demonstrated to have good directional forecasting ability.

By transforming our forecasting model into a trading model, we were further able to investigate the model's profitability. The results were compared to a buy-and-hold benchmark as well as to three different trading strategies commonly used by technical analysts. Two of these technical indicators represented variations of the Stochastics and thus allowed us to directly compare the forecasting performance of our model to its generic root. The third trading system was an arbitrarily chosen moving average system, which represents the class of trendfollowing trading models widely used by technical analysts.

The results of our profitability study showed that while the arbitrarily chosen technical indicators had problems in beating the buyand-hold strategy, our models had no difficulties in passing this criterion for both currencies. Taking the returns of buy-and-hold as a measure of the underlying trend rates in the data (Poole, 1967), it can be seen that the high excess returns of our models cannot be explained by a positive trend alone. In fact, the profitability of our models seems to be unrelated to the underlying trend in the currency, since our model yields a high rate of profitability in trending (as in the case of USDDEM) as well as in trendless (as in the case of USDJPY) markets. Adjusting for risk, using the methodology proposed by Thomas and Levich (1993), also had no substantial effect on the profitability of our models. Even though the trading strategy of the traditional Stochastics and moving average models resulted in a quite high annualized rate of return, they could not match the performance of our models. The 
dynamic modeling strategy utilized in this paper must therefore possess an important informational advantage over such models and, indeed, our forecasting analysis revealed that the good forecasting performance of our models is directly linked to the inclusion of error correction components.

The relatively small sample size used in this paper suggests that we should perhaps be cautious in putting too much weight on our results. However, to set against this the high dealing frequency of our models means that we are able to analyze 250 trading signals, which is in fact similar to the number of trading signals studied in the 'long-term' studies of Schulmeister (1987) and Menkhoff (1998). Since the profitability of our models persisted in two completely different market situations, we assign a certain statistical meaningfulness to our results.

\section{Appendix}

\section{Place Figure 1 Here}

FIGURE 1.-UUSDDEM development over forecasting period 


\begin{tabular}{|c|c|c|c|c|c|c|c|c|c|c|}
\hline & Lags & $L B$ & $L(1)$ & $L(4)$ & Trace & $\log$ & $S C$ & $H C$ & $A R C H$ & $R^{2}$ \\
\hline USDDEM & $\begin{array}{c}15 \\
\chi^{2}(6030) \\
p=.21\end{array}$ & $\begin{array}{c}6118.02 \\
\chi^{2}(9) \\
p=.0\end{array}$ & $\begin{array}{c}30.96 \\
\chi^{2}(9) \\
p=.42\end{array}$ & 9.24 & .21 & -33.3 & -33.9 & -33.09 & $\begin{array}{l}90.24 \\
65.94 \\
27.52\end{array}$ & $\begin{array}{l}.04 \\
.3 \\
.3\end{array}$ \\
\hline USDJPY & $\begin{array}{c}15 \\
\chi^{2}(6021) \\
p=.98\end{array}$ & $\begin{array}{c}5799.1 \\
\chi^{2}(9) \\
p=.0\end{array}$ & $\begin{array}{c}33.9 \\
\chi^{2}(9) \\
p=.54\end{array}$ & 7.93 & .22 & -33.3 & -33.9 & -33.1 & $\begin{array}{l}70.43 \\
72.59 \\
28.43\end{array}$ & $\begin{array}{l}.04 \\
.33 \\
.27\end{array}$ \\
\hline
\end{tabular}




\section{Place Figure 2 Here}

FIGURE 2.-USDJPY development over forecasting period

\section{References}

Cheung, Y-W, and Wong, C. Y-P. 1997. The performance of trading rules on four Asian currency exchange rates, Multinational Finance Journal.

Cheung, Y-W, and M.D. Chinn. 1999. Macroeconomic implications of the beliefs of foreign exchange traders, NBER Working Paper, No. 7417.

Clements, M.P., and Mizon, G.E. 1991. Empirical analysis of macroeconomic time series: VAR and structural models, European Economic Review, 35: 887-917.

Crucio, R., and Goodhart, C. 1992. When support/ resistance levels are broken, can profit be made? Evidence from the foreign exchange market, Discussion Paper No. 142, LSE Financial Market Group, Discussion Paper Series, July.

Cumby, R.E., and Modest, D.M. 1987. Testing for market timing ability, Journal of Financial Economics 19: 169-189.

DeGrauwe,P., and Decupere, D. 1992. Psychological barriers in the foreign exchange market, Centre for Economic Policy Research, Discussion Paper No. 621, London.

Diebold, F.X.; Garedeazbald, J.; and Yimlaz, K. 1994. On cointegration and exchange rate dynamics, Journal of Finance 49: 727-735. 
Diebold, F. X., and Mariano, R.S. 1995. Comparing predictive ability, Journal of Business and Economic Statistics 13: 253-263.

Dooley, M.P., and Shafer, J. 1983. Analysis of short run exchange rate behavior: March 1973 to November 1981. Chapter 3 in: D. Bigman and T. Taya (ed.): Exchange Rate and Trade Instability. Cambridge, Massachusetts: Ballinger Publishing.

Edwards, R.D., and Magee, J. 1966. Technical analysis of stock trends, John Magee, Springfield, Massachussetts, 5th ed..

Fiess, N.M. 1999. Technical analysis: an econometric approach, PhD Thesis, University of Strathclyde.

Feeny, M. 1989. Charting the foreign exchange markets, in C. Dunis, M. Feeny (ed.): Exchange rate forecasting, New York, 99-16.

Garman, M.B., and Klass, M.J. 1980. On the estimation of security price volatility from historical data, Journal of Business, 53: 1, 67-78.

Granger, C.W. 1986. Developments in the study of cointegrated economic variables, in: Oxford Bulletin of Economics and Statistics, 48: 213-228.

Hendry, D.F, and Mizon, G.E. 1993. Evaluating dynamic econometric models by encompassing the VAR, in: P.C.B. Phillips (ed.): Models, methods and applications of econometrics: Essays in honor of A.R. Bergstrom (Blackwell: Oxford, 1993)

Johansen, S. 1988. Statistical analysis of cointegration vectors, Journal of Economic Dynamic and Control, 12: 231-254.

Johansen, S., and Juselius, K. 1990. Maximum likelihood estimation and inference on cointegration. With applications to the demand of money, Oxford Bulletin of Economics and Statistics, 52: 169-210.

Johansen, S., and Juselius, K. 1992. Testing structural hypothesis in a multivariate cointegration analysis of PPP and the UIP for UK, Journal of Econometrics, 53: 169-209.

Johansen, S., and Juselius, K. 1994. Identification of the long-run and the short-run structure. An application of the ISLM model, Journal of Econometrics, 63: 7-36.

Lane, G.C. 1984. Lane Stochastics, in: Technical Analysis of Stocks and Commodities, May/ June.

Leoni, W. 1990. Möglichkeiten der Wechselkursprognose: Empirische Untersuchungen zur Informationseffizienz des Devisenmarktes, Gießen.

Levich, R.M., and Thomas, L.R. 1993. The significance of technical trading rules in the FX market: a bootstrap approach, Journal of Money and Finance, 12: 451-474.

MacDonald, R., and Marsh, I.W. 1997. On fundamentals and Exchange Rates: A Casselian Perspective, Review of Economics and Statistics.

Menkhoff, L. 1998. Examining the use of technical currency analysis, Journal of International Money and Finance, 17: 547-564.

Menkhoff, L., and Schlumberger, M. 1995. Persistent profitability of technical analysis on foreign exchange markets? Banca Nazionale del Lavoro, 
Quarterly Review, 193, 189-214.

Meese, R.A, and Rogoff, K. 1983. Empirical exchange rate models of the seventies: Do they fit out of sample?, Journal of International Economics, 14: 3-24.

Murphy, J.L. 1986. Technical analysis of the futures markets, a comprehensive guide to trading methods and applications, New York Institute of Finance, New York.

Neftci, S.N. 1991. Naive trading rules in financial markets and WienerKolmogorov prediction theory: a study of "technical analysis", Journal of Business, 64, 4: 549-571.

Parkinson, M. 1988. Extreme value method for estimating the rate of return, Journal of Business, 53, 1: 61-65. Poole, W. 1967. Speculative prices as random walks: an analysis of ten time series of flexible exchange rates, Southern Economic Journal, 33: 468-478.

Takens, F. 1981. Detecting strange attractors in turbulence, in: D. Rand, L. Young (Eds.), Dynamical Systems and Turbulence, Berlin.

Schulmeister, S. 1987. An essay of exchange rate dynamics, Wissenschaftszentrum Berlin für Sozialforschung, IIM Discussion Papers: Labour Market Policy, 87-8.

Sweeny, R. 1986. Beating the foreign exchange market, Journal of Finance 41: $163-182$. 